\title{
Serious Fun? Deleuze's Treatise on Nomadology
}

\author{
Dorothea Olkowski
}

In Anti-Oedipus, Gilles Deleuze and Félix Guattari analyze the manner in which what they refer to as deterritorialized flows of desire have been reduced to state, family, or religious hierarchies. Matter, capital, and libido are among the flows of desire for which nature and human nature are processes of production. The authors argue that there is really only one process of desiring-production, that now capitalism and psychoanalysis are inextricably linked, and that the former produces subjective abstract labor, while the latter produces subjective abstract libido. Thus although nothing exists outside of the socius, without its inhabitants, there is no socius: "they are strictly inseparable and constitute one and the same process of production." (Deleuze \& Guattari, Anti-Oedipus 340) This leaves one with the uncomfortable conclusion that social repression and psychic repression are one and the same mechanism, and insofar as the transition from primitive territories, to barbarian despots, to civilized capitalists, which they refer to as State power, has proceeded lock-step, there is possibly no place else to go. Or, even if there is another transition, it will only reinforce the forms of repression already in place.

At most, what seems possible is a level of interpretive examination of the social processes (social machines) in which the user is caught up (322). This process, referred to as schizoanalysis, would have to begin by focusing not on ego and id, nor on the sexual or other organs, but on the partial elements of the unconscious, "a pure dispersed and anarchic multiplicity, without unity or totality," the so-called "molecular functions of the unconscious." (323) Yet, it is clear that even to the extent that such an analysis is revelatory and to the extent that this schizophrenic line of escape (that is, a nomadic distribution) is even possible as the process of a schizo, one who is no longer an organized subject, who can "no longer bear . . . values, morals, homelands, religions, and private certitudes," it lies within and in relation to the socius (341). In other words, the

${ }^{1}$ Scholars have pointed out that Social production represents, at a molar level, what is produced, by desiring production, at a molecular level (see Smith 178). In other words, flows are molecular and their manifestations and representations-objects, symptoms, codes - are molar. 
schizophrenic investment is simultaneously a social investment and it is the task of schizoanalysis to reach the investments of the unconscious in the social field. Initially, this calls for a negative task "violent, brutal: defamiliarizing, de-oedipalizing, decastrating; undoing theater, dream, and fantasy." (381) But the negative task remains within the libidinal field of the unconscious. So at the same time, the positive task is the discovery of libidinal investments in the social field, the social nomadic distribution, thus the "nomadology," a social undoing of the organized and unified social field, a nomadic distribution of the socius that is not able to be captured by civilized capitalism. The question that emerges is whether or not this is actually the case, that is, is it possible to conceive of a social field that is not able to be coded by state, familial, or religious hierarchies, especially in the age of the axiomatic of capital?

\section{The Warrior God}

In their Treatise on Nomadology, Deleuze and Guattari seek to examine the parameters of State and judicial power through the lens of IndoEuropean mythology. To this end, they draw on the distinction between the Indian warrior god, Indra, and the figures Varuna and Mitra, the magician-king and the jurist-priest. They cite the scholar Georges Dumézil's thesis that going back to the $14^{\text {th }}$ century, the magician-king and the priest are interdependent and represent respectively, decision and action and intelligence and will. Mitra, the reasoner, generally opposes blood-sacrifice and upholds law while his counterpart, Varuna, is identified with violence (Dumézil 22, 66-7). But together, Varuna and Mitra regulate exchanges between those who make sacrifices and the gods, that is, they uphold the magico-religious "ritual law" and bind to the point of death those who "succumb. . . for an instant to . . . [their] humanity" by failing to deliver a promised (often human) sacrifice properly (104-5). Thus, they govern the realms of property, debt and loans (98).

From this situation there emerges Indra, the warrior god, leader of a band of "heroes" whose economic and sexual morality is distinct from that of the rest of society, for the heroes violate contracts, lie to the god Mitra, and unfetter Varuna's legally bound victims (98). Quoting Marcel Granet, Dumézil adds that "throughout the world this revolution [meaning the advent of the warrior] signals one of the great moments, constitutes one of the great openings of society to progress." (108) Attuned to this revolution, this great opening, Deleuze and Guattari identify Indra with their concept of the "war machine," which "in-itself" remains outside of sovereign authority and prior to its legislative power insofar as what they come to call the war machine in the guise of Indra operates against State power, both the sovereign and the law. 
They carry out this analysis in order to articulate the conflict between State power and its apparent adversary, Nomadic power, a conflict that began with ancient societies, that is, the primitive territories, but continued through the reign of barbarian despots and up to the present day of so-called civilized capitalists. Their analysis leads to the not so surprising conclusion that although Nomadic thought and action are relative to State thought and power, there are many more States and much more state power than there are Nomadic actors, and that the latter may even be a necessary component of State power, which manifests itself in our laws as much as our academic, religious, and social practices.

To augment their account of the warrior and the war machine, Deleuze and Guattari take up and compare the game of Chess to that of Go, which represent not merely forms of amusement (fun), but also serious forms of order and organization with significant repercussions. The former, they argue, is a game of State whose coded pieces have intrinsic properties determining their possible moves. Chess pieces bear specific names such as King, pawn, or knight, which determine the limits of their movements, their relation to all the other pieces and to the board. To this let us add that chess is a hierarchical game whose object is to catch the King. Players aim to dominate the center of the chess board, which has been compared to the sun at the center of the solar system. Playing pieces at the center have the greatest possible freedom of movement around the board, thus opening moves (of which twenty are possible) are important. ${ }^{2}$ Once a player controls the center, they can expand their control to the edges of the board because chess is a tactical game involving a single battle directed toward the specific end of putting the King in check (see Bozulich).

By contrast, Go pieces are anonymous, simple arithmetic units with no intrinsic properties operating in constellations that function primarily to capture territory. Go is for this reason described as largely a game of strategy, an "imperial game where each player seeks to enclose more territory on the board than their opponent."3 A player has 361 possible opening moves, thus players are more often surprised by their opponent's moves and must constantly rethink their strategy, that is, their overall plan for moving their playing pieces and for capturing territory around the edges of the board, where it is easy to obtain, then moving to the center only much later. Thus, many battles may take place at the same time at different parts of the board and players must quickly learn to

2 See www.chessity.com/blog/501/Controlling the Center_Opening strategy and the British Go Association's website: www.britgo.org/learners/chessgo.html (accessed 20 April 2016).

${ }^{3}$ Again, see www.britgo.org/learners/chessgo.html. 
diversify, to place playing pieces all over the board. ${ }^{4}$ Unlike in Chess, the Go pieces (smooth black or white stones) are placed at the intersections of squares and not within them, emphasizing that the stones surround the area they are capturing and do not merely occupy it.

Both are war games, but Chess is an institutionalized, regulated, and coded war with front lines and rear skirmishes. It is arranged in closed spaces with clearly delineated sides that must be protected. The pieces maintain one to one relations with other pieces, so that together their moves constitute the game's overall, stable and functional, therefore stratified structure (Deleuze \& Guattari, Plateaus 40, 352-3). Their intrinsic properties and qualities can be characterized as the subject of statements that become the subject of enunciations when spoken by the chess player (for example "bishop pair" or "king hunt")—-thus chess's semiological character as a system of signs (253). In a sense, the player, like a minister of defense, speaks as an institution through the chess pieces from within the standpoint of their internal natures and intrinsic properties.

Given their uniformity and anonymity, the Go pieces play a third person function to the point that relations on a Go board are external to the playing pieces. The skirmishes of Go lack precise battle lines and are instead organized around constellations of units arranged in an open, homogeneous, smooth space, which originally belongs to no side, the point being to obtain and hold territory wherever possible utilizing strategies such as bordering, encircling, or shattering the other players held territory (253). Battles in different parts of the board take place independently of one another and are difficult to coordinate. No matter how badly things appear to be going for a player, its preferable to keep all options open as far into the game as possible and under duress, to head to open territory. Deleuze and Guattari address this strategy in a manner that implies the existence of war-like situations far beyond that of a board game. "Make the outside a territory in space; consolidate that territory by the construction of a second, adjacent territory; deterritorialize the enemy by shattering his territory from within; deterritorialize oneself by renouncing, by going elsewhere." (253)

In fact, the juxtaposition of Chess and Go serves a serious purpose. It is the image of the games played between State power and what they refer to as the war-machine, which itself is an image of the relations between Mitra-Varuna and Indra. The so-called war machine is not always or even usually actually engaging in bloody battles, but in various guises - intellectual, sexual, artistic, scientific, philosophical—sets itself up in opposition to the order of the State apparatus-namely, the King, the priest, and the law (254). The question these two forms of play

\footnotetext{
${ }^{4}$ See www.magicofgo.com/roadmap9/chess\%20and\%20go.htm.
} 
problematize is the question of the nature of creative and original thinking and acting, not only in relation to political power but also in each of the social and creative spheres mentioned above. What problematizes their relation is that the two forms of conflict, the State and the war machine, the two games, especially when played on a grand scale, require one another.

In the modern state as in Chess, at least since the time of Thomas Hobbes' great treatise, Leviathan, the more citizens obey, the more they are said to be free because they have used their reason to follow the law, to operate internally within the confines of the law. By contrast, the Go player must be a thinker of the outside, sometimes violent - striking like lightening - and always discontinuous in appearances. But if the Go player operates with strategies of attack and retreat rather than lawful reason, what is the nature of this kind of thinking and acting? Is it enough to strategize, to form bands against the State, to play the nomad with no paths or land, to territorialize and as quickly to turn around and deterritorialize, to think always in terms of continuous variations of variables? Or, is there something more needed-something that can interfere with the big game played between the King, the priest, and the law on the one hand and the nomad on the other?

\section{Nomos and Polis}

Deleuze and Guattari contrast the nomadic nomos (culture) designated by the game of Go - the war machine that territorializes and deterritorializes by arriving from outside, from the boundaries-with State power, the polis, which codes and decodes space by means of institutions that impose values and laws from within. The point of this distinction seems to be that the warrior utilizes bands of playing pieces to ward off and prevent State power from forming, a reversal of Hobbes' Leviathan, where the power of a rational constitutional monarch must be absolute in order to manage the appetites and desires of the citizens. Nevertheless, the relation between the two is close. The Go player, the warrior, is not simply Hobbes" "nature," the war of all against all." Dating back to "the remote ages of humanity," there have always been so-called primitive nomadic cultures, Go players on the periphery of centralized States and its Chess players, according to the law of the interior and the trajectories of the exterior (360).

State sovereignty reigns over only what it can appropriate locally. Thus, its "outside" does not consist in other states but can take the form of industrial complexes like big oil, religious formations such as Christianity or Islam, or media empires, like News Corp or Disney. Or, it arises as a new tribal society of local minorities, like the hippies described by Marshall McLuhan in an interview in 1994: 
They want nothing to do with our fragmented and specialist consumer society. Living in the transitional identity vacuum between two great antithetical cultures, they are desperately trying to discover themselves and fashion a mode of existence attuned to their new values; thus the stress on developing an "alternate life style." We can see the results of this retribalization process whenever we look at any of our youth - not just at hippies. Take the field of fashion, for example, which now finds boys and girls dressing alike and wearing their hair alike, reflecting the unisexuality deriving from the shift from visual to tactile. The younger generation's whole orientation is toward a return to the native, as reflected by their costumes, their music, their long hair and their sociosexual behavior (McLuhan, 6).

But this latter type of "army" is unstable insofar as it consists of bands of warriors who congregate for war, then disperse, inhibiting the authority and power of a single leader. In this context, the war machine serves as a concept replacing the old words "revolution" or even "social change." It is a game played by bands of persons, whether they band together to steal or to act in high-society, formally exterior to rational law but never truly independent, just as the State is never truly independent of either the global, well-organized or regional, tribal war machines.

Deleuze points to the shifting "tension-limit" between the Nomad and the game of State exemplified in the dynamic relations and material forces characterizing the Gothic cathedrals of the $12^{\text {th }}$ century, and the tendency toward mathematical figures and equations organizing surfaces and volumes necessary to building bridges in the $18^{\text {th }}$ and $19^{\text {th }}$ centuries. Gothic structures being longer and taller than the Romanesque, they required careful cutting of stones so that a building might support itself by the strength of its shape and by the cut of the stones, "a series of successive approximations." (Deleuze \& Guattari, Plateaus 364) Stone cutting or "stereometry" is a descriptive geometry, a nomad science, that like Go, calls for shaping forms to suite given conditions. Its principles involve construction based on drawn projections, specific instruments such as chisel and mallet, and rules for utilizing these in the correct order and manner (Warren 1-2). Thus, as has been pointed out, the object of the knowledge of nomad science is the behavior of the materials to be worked with rather than the sedentary distinction between matter and form (Boundas 21). Nevertheless, the application of these principles "will depend considerably on the ingenuity of the designer." (Warren 2)

Of course some cathedrals built by journeymen did collapse, but also, in an effort to speed up production, State science appropriated aspects of nomad science to stabilize it. For the cathedrals, the State 
excluded the journeymen, utilizing unskilled workers who followed templates to cut stone. It managed the construction sites, dividing theoretical and practical workers, both of whom were subject to sedentary State power (see Querrin; and Deleuze \& Guattari, Plateaus 356). Thus, constants were extracted from variables and the nomadic practices of the Go player - the placing of variables in a state of continuous variationdisappeared. In the same manner, Edmund Husserl distinguishes the round, as a vague or nomadic essence, from the circle, a theorematic, fixed essence and a constantly varying variable.

Not surprisingly, Go (the Japanese name for the ancient Chinese game wei-ch'i), has been "a favorite game of strategy of Chinese generals, statesmen, and literati from the former Han dynasty (206 B.C. -8 A.D.) to the times of Mao Tse-tung." (Boorman 5) In his own writing, Mao compares the campaigns and battles of his guerilla's to the game of weich' $i$, stating that both seek to "dominate spaces on the board" in a form of encirclement (6-7). Mao's particular game of wei-ch'i lasted twenty-two years and extended over all of China (8). Wei-ch'i is essentially a protracted war whose formations are non-linear and discontinuous, where capture is achieved through encircling by many coordinated groups. As such there can be no secure front line or safe area in the rear and victory is always relative to the territory encircled (23-4). This was apparently not only Mao's strategy as those among us who still live with the memories of the US war in Vietnam can quickly draw our own conclusions.

Today, Go players exist in the form of extremely privileged persons of tremendous wealth and extreme political ideologies (the 1 Percent) as much as among minorities (Black Lives Matter or the 99 Percent) and armed bands opposing state power (for example, the recent militia takeover of an Oregon bird-sanctuary in the U.S.A.). Clearly, the nomadic game is wide open to anyone who is capable of playing it. It need not be what we in the U.S.A. like to call "progressive"; in fact it may be deeply regressive given the concern of so-called "primitive societies to ward off or avert that monster" that is the State apparatus, the conserver of mechanisms of power (Deleuze \& Guattari, Plateaus 360).

\section{The Epistemology of Nomad or Minor Science}

Deleuze and Guattari argue that the war machine is supported by an epistemology that perpetuates nomad or minor science in opposition to royal or State science. But how? State science operates by setting up theorems. A theorem is mathematically defined as "a statement that can be demonstrated to be true by accepted mathematical operations and arguments. In general, a theorem is an embodiment of some general principle that makes it part of a larger theory. The process of showing a 
theorem to be correct is called a proof." ${ }^{5}$ In philosophy as in science, this is a typical practice, a way to get one's foot in the door by asserting one's definitions, then moving from definition to example, from an essence to its properties.

By contrast, the war machine problematizes. Deleuze and Guattari's treatise on Nomadology is organized with axioms, propositions, and problems. Axioms are defined mathematically as self-evident propositions (true without proof), and propositions are simply statements that may be able to be logically true or false, except in the case of paradoxes. Problems are merely exercises whose solution is desired. ${ }^{6}$ As I have argued elsewhere, "Deleuze, in problematizing philosophy, is setting it in motion, making no claims about the nature of the world, providing no taxonomies or hierarchies of its inhabitants, no claims about what is or is not true." (Olkowski 61) In this, he follows the practice of the Greeks who distinguished between "problems" (roughly, the construction of various figures) wherein one sets up the problem and moves from the problem to its conditions, and "theorems" (establishing the properties of said figures). ${ }^{7}$

Problematics institutes Deleuze's "hydraulic model," the model of flows, flux, and consistency characterized by what he calls the "intensive concept," which is described as an "event as pure sense." Events have meanings that are given formally without denoting lived experience or scientific states of affairs, thus they lack conditions of reference in general. They consist of multiple variations but their consistency is defined by internal components, components internal to the sign in which they appear. This is the difference between proscribing all the rules and laws for establishing an institution, then setting them in motion-like a Constitution - and describing the workings of a society from inside, how all of its shifting functioning and nonfunctioning parts - race, class, culture, geography, education, wealth - relate to one another internally. Likewise, it is the difference between characterizing Deleuze's own philosophy as the instantiation of, for example, chaos theory, which would then be applied to every problem as a formal theorem and Deleuze's stated preference for axioms, propositions, and problematics. The methodology of problematics situates the intensive concept outside of the mundane propositions in which it might have been enshrined as well as outside the propositional functions, variables, and truth value of prospects, that is, outside of formalist logical principles (Deleuze \& Guattari, Philosophy? 144).

\footnotetext{
${ }^{5}$ See http://mathworld.wolfram.com/Theorem.html (accessed 18 April 2015).

${ }^{6}$ See http://mathworld.wolfram.com/Problem.html (accessed 15 December 2016).

${ }^{7}$ See http://mathworld.wolfram.com/Problem.html (accessed 23 April 2016).
} 
This model has been formulated by Jean-Paul Sartre as the nothingness of being that leaves us condemned to freedom, and more recently by Michel Serres in terms of the clinamen, the concept of atoms falling in the void, "the smallest angle by which the atom deviates from the straight path (Deleuze \& Guattari, Plateaus 361). Rather than following a determinate path prescribed by a causal sequence of events, atoms swerve and commence a movement that appears to "snap the bonds of fate, the everlasting sequence of cause and effect" (in Mapstone 8; she quotes Lucretius 44). From this point of view, to exist, to be a being, is to escape the causal determination of the past; it is to deviate moment by moment, where each new moment is an effect of the past but breaks completely with that past, which can then be defined as nothingness. Deviation from a state of equilibrium that is mute, motionless, and passive, governed wholly by natural forces, begins with what Serres refers to as laminar flow, the non-turbulent motion of a fluid in layers in smooth space (Serres 7). ${ }^{8}$ In water, laminar flow is "water flow in which the stream lines remain distinct and in which the flow direction remains approximately parallel without cross currents and eddies," but at velocities . . . the stream lines become non-parallel and momentum becomes chaotically distributed, giving way to disorder, that is, to turbulence. ${ }^{9}$

Yet even in movement, there is stability as exemplified by Plato's spinning top (see Republic 436d). The faster its movement, the more it rests on its bottom point; it moves by translation, every point on its body moving in the same direction at the same speed; its axis may lean without tipping the entire top; it may rock, oscillating around a point; it both moves and is at rest (Serres 28-9). Archimedes' text, On Plane Equilibrium, situates the clinamen as a very small angle of deviation from balance or equilibrium (from zero mathematically). The clinamen is a differential such that whatever exists must do so as a deviation from the fixed position as a displacement in relation to zero (17, 20-1). Philosophically, this means that "we do not work with reason, science, or hands except through deviation from equilibrium. Everything is deviation from equilibrium, excepting Nothing. That is to say, Identity." (21)

The problematic in philosophy as in science is for this reason called an affective dimension of thought insofar as it does not proceed according to rational theorematic procedures but rather occurs as the

\footnotetext{
${ }^{8}$ Planar laminar motion can be illustrated by pushing the top of a closed book sideways; the bottom does not move and the top shows the maximum motion. See: http://demonstrations.wolfram.com/LaminarFlow/ (accessed 27 April 2016); and Deleuze \& Guattari, Plateaus 361.

${ }^{9}$ See:

www.dwa.gov.za/groundwater/groundwater_dictionary/index.html?laminar_flow.htm (accessed 13 May 2016).
} 
event, that is, as the effect of "metamorphoses, generations, and creations," an insurgency within philosophy or within sciences themselves as they are routinely carried out. ${ }^{10}$ As events, problems-exercises whose solution it desired-constitute the war machine of nomad science and nomad philosophy.

As the Nomad, the Go player, the warrior, exerts pressure on the State from outside, the State is reproducing itself, ensuring identity and public recognition (Deleuze \& Guattari, Plateaus 360). It is on guard and always ready to appropriate what it can of Nomad thought, even while repressing or banning or marking as irrelevant what it cannot use. Think of how often this happens in philosophy, where one must always address the status quo, those professional philosophers who have become authoritative and who preserve and perpetuate the centrality of their expertise in order to ensure that thinking which problematizes what everyone "knows" to be the case is restricted or silenced, anything to prevent turbulence and constrain movement. As in solid physics, fluids are reduced to solids, measured, and hierarchized, defeating the turbulence.

\section{Does a Nomad need the State, Does Nomad Science Need Royal Science?}

Serres argues that Leibniz's psychology of freedom remains linked to the declination of atoms in the void, the infinitesimal angle of the trajectory, and the imperceptible rupture of spatial symmetry, because both identity and indiscernibles (entities impossible to clearly distinguish) regulate his universe so that indiscernibles cannot be identical (Serres 32; see also Black). Nevertheless, "atoms tend, indefinitely, towards stability," but it is the stability of their conjunction, their joining together in decline (Serres 34). In other words, stability is as transient as the bodies and worlds thus formed (48). Serres argues, following Lucretius that, "the world, objects, bodies, my very soul are, from the time of their birth, adrift . . . . they irreversibly fall apart and die," and so our soul, an amalgam of atoms and void, is mortal. "The universe, as it is, as it goes on, as it transforms itself, is mortal. The earth shakes and the house falls. All conjunctive tissue is sapped by the void. . . And only the void is immortal, like the particles." $(34,44)$

Deleuze and Guattari, by contrast and more subtly, focus on Serres' statement that "nothing may be seen or thought to be inclined without reference to something that is not [inclined] . . . a water lever, a plumb-line, a measuring stick. A cube in space, a Euclidean system." (45) To this list, Deleuze and Guattari add the war machine, which is invisible

10 The previous three paragraphs refer to ideas in Deleuze \& Guattari, Plateaus 361-2. For insurgency, see Boorman 53-4. 
without a State. This implies that ontologically, the relation of the Nomad and the State, of the Go player and the Chess master is that they are $a$ single field of action. For its part, the State appropriates the nomadic essence (anexact but rigorous), while the Nomad cuts loose the contents of royal science (Deleuze \& Guattari, Plateaus 367). Are we too quick to subvert the Nomad to the State? The Nomad is not pre- or post- State, its procedures are not pre- or post- science, Go is not pre or post- Chess. Rather, Nomad thought is that arena in which the scientific field, the philosophical position, the aesthetic, or political, or sexual field is problematized and so appears in an entirely different manner (367). It can be said that the State produces idealizations, ideal circles, ideals of beauty, ideals of the social contract, ideals of sexual norms, and the Nomad replies with round things, graffiti, tribalism, polymorphous perversity, yet Deleuze and Guattari are not sanguine about this relationship.

As academics and intellectuals know only too well, the State avoids empowering them, but hopes to make them dependent giving them an imaginary autonomy, while their real task is to reproduce what is already known (368). Yet, somehow, some of them continue to make trouble, to reorganize the given social field of forms that organize matter and matter prepared for forms. Nomad thought does not prepare matter which when problematized is already a form of content, and form is always, already a chosen matter of expression (369). This is not materialism. It requires that we understand that this theory of problematics, this theory of the clinamen, utilizes differential equations, which articulate the decline of atoms and are inseparable from the intuition of variation.

This means that rather than producing theorems, Nomad concepts are singularities, always in variation. In physics, a singularity is that point at which there is a breakdown in the geometrical structure of space and time. The most obvious case of this is the big bang 13.7 million years ago, but collapsing matter forming a black hole is also thought to have a central singularity. ${ }^{11}$ There is no way to causally determine the future of a black hole based on its causal past, and given its theoretical counterpart, the white hole, there would be no way to causally determine anything that might emerge from it. The concept of singularity is a theoretical construct tied to the theory of general relativity, but Deleuze and Guattari extend it conceptually to mind: in thought the singularity is a problematic theoretical construct that deviates from the theorematic. Structure breaks down and both the causal past and the causal future are indeterminate, which means, they are situated as varying variables.

Thus, although Royal Science established itself in relation to the theory of Universal Gravitation, a constant relation for all variables,

\footnotetext{
${ }^{11}$ See http://plato.stanford.edu/entries/spacetime-singularities/.
} 
measuring no more than two bodies at a time, new fields in physics seem not to be reducible to the model of gravitational forces (Deleuze \& Guattari, Plateaus 370). Why then should philosophy or art or politics or sexuality be any different? Something always prevents the Nomad from being completely introjected into the State, granting them the position of a "minor" voice. Nevertheless, the cathedrals at Orleans and Beauvais collapsed at the end of the $12^{\text {th }}$ century and the State called out for control in the name of safety. Yet, in the interactions between Nomad science and State science, it appears that the former invent problems whose scientific solution depends on the manner in which Royal or State science theorizes the situation and organizes the work that materializes it (374). We can say the same for thinking. The signifying chain at some point will be theorized in relation to true and false propositions. The two games are always being played simultaneously.

So, the big question remains. Can thought be extracted from the State model? Can we play Go without playing Chess? Can nomadic warriors exist apart from State order? If we accept that there are two kinds of sovereignty, one the imperium or authority founded in mythos (Varuna) and the other, the legislative and juridical logos (Mitra), there may persist an event between them. Keep in mind that in modern philosophy it is thought which invents and validates the "fiction of a State," which separates murderous rebel subjects in Hobbes' Nature from rational consenting subjects, serving in this way as the interiority, the moral center of rationality. As the State extends its authority in thought, it also sanctions thought as a unique and universal form (375).

What this means is that philosophy or sociology or psychoanalysis are State forms of thought and that the less attention we pay to the role of thought, the more conformist it is likely to become. However, it is also the case that the State is a contingent development that might not have appeared. Keep in mind that Nomad thought is not an effect of the State. It is a force that appears to remain relative to State thought possibly without being able to undo it.

For every warrior, for every tribe, there are many more States and much more state power, which manifests itself in our laws as much as in our academic, religious, and social practices. Yet the war machine is not necessarily seeking war or revolution-only displacement, like Moses launching into the desert or Antonin Artaud reviling and refusing language - each seeking to evade appropriation by the State and its figures, the King, the Priest, and the lawmaker. But sometimes in the end, the nomad (including the billionaires or the NRA) returns countering with an even more massive State (417). So, which will it be for us? Will we be returned from a nomadic line of escape with an even more powerful State than that which we fled? Can we play our game against the State in the form of guerilla or minority action risking having our thought and action 
adapted by the State and used against us? Can we refuse to speak and write in theorems, utilizing a creative line of escape, making war by creating something else? Whichever our trajectory, this is not to go up against the State, it is rather, to persist in relation to it.

\section{Works Cited}

BLACK, Max. "The Identity of Indiscernibles." Mind. Vol. 61, no. 242 (April 1952): 153-164.

Boorman, Scott. The Protracted Game: A Wei-Ch'I Interpretation of Maoist Revolutionary Strategy. Oxford: Oxford University Press, 1969.

Boundas, Constantin. "What Difference Does Deleuze's Difference Make?" In C. Boundas (Ed.). Deleuze and Philosophy. Edinburgh: Edinburgh University Press, 2006): 3-30.

BozUlich, Richard. "Chess and Go: A Comparison.” Chigasaki: Kiseido Publishing Company.

www.magicofgo.com/roadmap9/chess\%20and\%20go.htm. Accessed 20 April 2016.

CurIEl, Erik and BoKUlich, Peter. "Singularities and Black Holes," The Stanford Encyclopedia of Philosophy (Fall 2012 Ed.): https://plato.stanford.edu/archives/fall2012/entries/spacetimesingularities/. Accessed 15 April 2017.

Deleuze, Gilles, and Félix Guattari. Anti-Oedipus. Trans. Robert Hurley, Mark Seem, and Helen R. Lane. Minneapolis: University of Minnesota Press, 1987.

-. A Thousand Plateaus. Trans. Brian Massumi. Vol. 2 of Capitalism and Schizophrenia. Minneapolis: University of Minnesota Press, 1987.

-. What is Philosophy? Trans. Hugh Tomlinson and Graham Burchell. New York: Columbia University Press, 1994.

DuMÉZIL, Georges. Mitra-Varuna: An Essay on Two Indo-European Representations of Sovereignty. Trans. Derek Coltman. New York: Zone Books, 1988.

LuCRETIUS, On the Nature of the Universe. Trans. R.E. Latham, revised by John Godwin. London: Penguin Classics, 1994. 
Mapstone, Susan. "Non-Linear Dynamics: The Swerve of the Atom in Lucretius' De Rerum Natura." (2007). The London Consortium Humanities and Cultural Studies Programme 2004/5: http://citeseerx.ist.psu.edu/viewdoc/download?doi=10.1.1.550.2252 \&rep=rep1\&type=pdf. Accessed 15 April 2017.

McLuhan, Marshall. "Playboy Interview: Marshall McLuhan." Playboy Magazine (March 1969): 26-63.

OlKowsKI, Dorothea. Gilles Deleuze and The Ruin of Representation. Berkeley: University of California Press, 1999.

QuERrin, Anne and Boundas, Constantin, “Anne Querrien, La Borde, Guattari, and Left Movements in France, 1965-81." Interview. Deleuze Studies, Vol. 10-3 (2016): 395-416.

SERrES, Michel. The Birth of Physics. Trans. Jack Hawkes. Manchester: Clinamen Press, 2000.

SMITH, Daniel W. Essays on Deleuze. Edinburgh: Edinburgh University Press, 2012.

WArren, S. Edward. Stereometry: Problems in Stone Cutting. New York: John Wiley, 1875. 